\title{
AN INTELLECTUAL HISTORY OF NATIONAL ACCOUNTING
}

\author{
Review of $A$ History of National Accounting by Andre Vanoli (IOS Press, \\ Amsterdam, 2005)
}

\section{INTRODUCTION AND OUTLINE}

The world never sleeps and economies do not stand still. As the scope, sophistication and complexity of economic transactions increase, new products appear and the institutions engaged in these exchanges themselves change. The nature of economic relationships is continually being transformed, as activities appear more ambiguous and the interpretation of economic statistics grows ever more difficult. The national accountant is increasingly being called upon to don the mantle of a shaman - expected to assume the crucial role of an intermediary between a real material world and a virtual representation constructed from partial and selective statistical observations. To interpret these phenomena, meaningfully and with integrity, economic statisticians should be well versed in a catechism that teaches the skills and knowledge to undertake this difficult task in an honest and effective manner. They equally require a relevant accompanying data framework to guide official efforts to gather information consistently and to incorporate coherently and according to well-defined principles and recognized international standards the many subtle judgments necessary to complete the overall picture of the economic system. But when the conceptual foundations of the present model of the national accounts are being progressively undermined by the shifting quicksands of economic theory, legal intervention, exogenous political determinations and the growing global nature of many transactions, even this may not be enough.

The national accounts are a statistical talisman, emblematic and "inclusive" in every sense of the expression. Many people use the national accounts for different reasons and this review outlines first the purposes of national accounting and its conceptual legacy. It then describes in more detail the structure and contents of this thoughtful book, before considering the influence of history on the development of national accounting and the challenges facing practitioners in their efforts to keep accounting procedures both practically useful and conceptually and theoretically relevant. In the end, it is necessary to ask not only whether the national accounts portray what many observers would like them to show but also whether, even in a "pristine" macroeconomic sense, they still provide the best representation of what they are supposed to measure and meet policymakers' requirements.

Note: The reviewer is grateful to Lars Osberg for his helpful suggestions to improve the paper and to Derek Blades for reading an earlier draft. Neither, of course, is responsible for any remaining errors or oversights. by Blackwell Publishing, 9600 Garsington Road, Oxford OX4 2DQ, UK and 350 Main St, Malden, MA, 02148, USA. 


\section{The Use of National Accounts}

The national accounts were originally designed to inform current national macroeconomic policy, by supporting macroeconomic analysis to guide fiscal decisions and providing a conceptual basis for determining the form of long term strategic development and structural reform. The accounts present a comprehensive synthesis of all the contemporary economic transactions in an economy where these are summarily recorded, usually, over the period of a year. To ensure comprehensive treatment, as well as overall consistency and coherence, these flows are matched to observed changes in the economy's asset holdings between the beginning and end of the year. As a statistical exercise, national accounting is more than just a procedure to generate politically endorsed single indicators of national progress such as gross domestic product (GDP) and income per head plus associated estimates of relative change in these macroeconomic aggregates. The framework provides the primary, universally acknowledged, means of assessing the effectiveness of macroeconomic policy and relative burden and benefit of fiscal relationships between the government and the people - and at the more shadowy cusp of these relationships between income generation, taxation and social redistribution via transfers and subsidies, social considerations begin to overlay the uniquely economic concerns of policy and enter into the domain of national accounting.

National accounts present information about domestic output, trade in goods and services, savings and investment and taxes, and how all these variables are inter-linked to each other in a logical and articulated manner within the domestic economy. They provide a relevant platform for investigating overall current material living standards, as measured by the yardstick of total household consumption; and for reviewing the foundation for future living standards, as indicated by the amount of investment or, more precisely, gross fixed capital formation in different sectors. Produced annually and, in a number of cases, quarterly, the national accounts reveal the extent of economic dynamism in a country and thereby underpin both public and private initiatives to encourage greater efficiency and productivity in the real sector. The accounts support policies that go beyond the political immediacy of stabilization and inflation control and a contemporary, somewhat debatable, short term emphasis on the psychology of "fine tuning." Involving ritualistic attention, at fixed predetermined dates, to miniscule manipulations of interest rates, this "tweeking" of monetary policy seems intended to maintain economic activity mostly by keeping in balance a potentially risky consumption spending - net wealth reduction equation. Based, collaterally, on potentially volatile paper asset values that can collapse like a pack of cards when unemployment rises and buying and debt repayment power correspondingly collapses, this line of approach involves mortgaging the future for the sake of the present. It does not always fit comfortably with policies of sustainability developed within the context of the real economy and wider statistical milieu of national accounting.

\section{Overview And Content}

In his masterful and scholarly study, originally in French, Andre Vanoli does much to fulfill the requirement for an all-embracing text to satisfy the interests of 
practicing statisticians, policymakers and informed users of the national accounts. He has produced a fascinating book, which is both an historical treatise and information packed reference source on national accounting. The book tells a chronological story, providing intuitive insight into the description of the emerging structure of macro-statistical systems over the centuries. The treatise explains the progress of national quantitative measurement in relation to economic thinking about markets and prices that has slowly evolved around a conceptual and methodological Keynesian logic. And, as a reference volume, it helps data practitioners and macro analysts understand the underlying components constituting the national accounts and the encompassing framework that defines how those elements fit together. The compilation of such a comprehensive and relevant overview is hardly surprising; the author was one of the principal architects and authors of the 1993 System of National Accounts (SNA) and he has worked extensively for more than half a century in this field. His account of how some of the more complex problems placed on the table during the 1993 SNA revision were resolved is particularly worthy of attention because it reflects the fine balance that must inevitably be struck between theoretical ideals and an essential pragmatism demanded of operational practice.

This book is a significant milestone in national accounting. With its wideranging oversight and interpretation of the ideas behind the formulation of successive SNA standards, the work has taken on the nature of a statistical thesaurus. To paraphrase Roget, the arguments are clearly presented "in a language that fitly and aptly describes the ideas according to their signification," which hold attention by being written in a "present historical" reportorial style. The commentary is backed up by extensive end-section notes supplemented with appendices and topic specific observations posted to accompanying boxes. Along with descriptive references to relevant documentation in annotated bibliographies accompanying each chapter, these reflect the author's internationally acknowledged intellectual authority in this field. Vanoli's crusading zeal is readily apparent in the challenges he poses to several long cherished concepts and conventions as he proceeds along a route that traditionally traces the well-trodden analytical path from careful empirical observation to organized scientific interpretation - as exemplified in his passionate concern to draw attention to the environmental impacts of economic development and to the real outcomes of social spending.

Statistical systems, and the national accounts are no exception, need to be linked to theoretical constructs. By incorporating landmark advances in economic theory to focus on data collection priorities, the development of national accounting has led to a better understanding of the complex structure and interrelationships of economic transactions. The accounts identify the distinct roles of different institutions and how, implicitly, the various mandates and incentive systems of corporations, households, governments and non profit institutions motivate agency behavior and influence events and actions which are not driven, in all cases, by the forces of economic rationality and the market. Over the years, national accounts have been an essential tool of policymakers, helping to guide their decisions (albeit not always wisely or appropriately).

Chapter 1 briefly describes the first two and a half centuries of national income estimates, leading up to the emergence of national accounting during the 
fascinating but highly unstable period of the 1930s and 1940s. It intriguingly recalls some of the turbulent discussion and debate of those early days, such as between the Dutch and Scandinavian academics and the British, and how, after initial post-war agreement on the desirability of harmonization, officials from America, Britain and Canada (the first country to embark on the regular elaboration of official national income estimates) began to drift apart. The eventual upshot being a decision by the Americans to follow their own path with the unfortunate result that, over the next half century, the U.S. authorities did things differently compared with the rest of the world.

Chapters 2 to 4 present the successive accounting structures and their international harmonization. They describe the associated integration and standardization of data required to produce a complete, coherent and fully articulated system. The chapter on developments in French national accounting reminds readers of the radical positions the French have taken in the past on separating market from non-market transactions, an issue only partly dealt with by institutional sectoring, on the relevance of basic prices and of their significant contributions to the area of satellite accounting.

The third part of the book (Chapter 5) presents national accounting as a statistical synthesis that provides, through a standard consolidated framework for integrating and articulating economic transactions, a clear raison d'être for the adoption of particular compilation and estimation procedures. In outlining these and defining the methodology for balancing and reconciling the accounts, the ensuing discussion lays out the assumptions and conditions for incorporating the various imputations, some of which are substantial, necessary to complete the system.

The fourth section, Chapters 6 to 9, is dedicated to concepts and theory and stands apart from the rest of the book. It is, in many ways, the most absorbing part of this study, and deserves detailed attention, shifting the emphasis away from an automatic "ISO9000" technocratic response to SNA classification and procedural questions. Solutions are suggested that are more interpretative but they usually require difficult imputations. Chapter 6 , in particular, reviews the role and significance of government and the controversies surrounding the measurement of official output and public sector activities. There is also a preliminary discussion of basic valuation concepts but the issue of prices is considered in more detail in Chapter 9 where the matter of international comparisons is taken up.

Chapter 10 concludes by considering the uses and current status of national accounting, hinting at explanations of why monetary policy appears to have asserted its authority over the management of the real economy and why, recently, strategic macroeconomic analysis has been relegated in some countries to an "also ran" role. This is followed, unusually, by a short "general outlook" chapter touching on some political concerns, plus a separate coda or "postscript" (what the author refers to as a "postface") that partially explains why he took a participatory, yet arm's length, almost existential, third party perspective on the characteristics of national accounting. Overall, the book evenly divides between history and synthesis in the first five chapters and theory, debate and subjective evaluation in the remaining chapters. There is an interesting and selective annotated bibliography following each chapter-to which additional reference can be found in the 
separate author index. Readers will find this more useful than a conventional bibliography because many of the references are accompanied by a brief commentary as to their relevance and specific contribution to the arguments presented.

\section{IsSUES AND APproaches}

The book comprehensively covers in different chapters the main controversies surrounding the use of national accounts. It discusses the problem of identifying welfare in a system designed primarily to provide information about the production of material goods and services, alongside their distribution to institutions and related consumption within a market context. The author emphasizes the difficulty of measuring the true extent to which current production and ever-rising consumer demands undermine future sustainability by drawing on the stock of exhaustible non-renewable natural assets, the full costs of which have not been accounted for or paid. Vanoli also confronts both the statistical and conceptual dilemmas posed by having to reconcile, within the market exchange system on which the national accounts are calculated, the underlying utility value of non-market goods and services consumed by households with their nominal administrative and imputed value, based mostly on cost.

In a work of 500 plus pages, it is impossible to do proper justice to every one of the many ideas and interpretations of statistical meaning presented. Two crucial factors, nevertheless, underlie how observers see the world through statistics and, specifically, the national accounts. One is history, and the wealth of accumulated knowledge acquired from past events and experience that can be brought to bear on a general understanding of socio-economic phenomena. The other is theory. As befits a book of this title, a brief review of the way history has shaped the structure of national accounts is prerequisite. The essential pragmatism inculcated by this experience impinges, in turn, on theory, sometimes for good although, occasionally, for bad. In the end, as Orwell noted, history provides an understanding of the past that enables people to control the future; but past events, however fascinating, turn out to be of little value unless they can provide guidance on how to conduct and improve that future.

\section{The Legacy OF History}

What exactly motivated early researchers to carry out, independently, so many initially ad hoc and highly detailed data gathering exercises? In the 18th century there were no economic "rules" or relevant theories, other than some dubious mercantilist thinking, to guide their activities. Vanoli suggests that the individual initiatives of these early researchers were motivated by a personal intellectual curiosity and also by "honest minds concerned about public matters." Certainly, in the late 18th and 19th centuries, there was a prevailing philosophy to measure things in response to a more general appeal to use scientific rigor in the search for basic truth. But more than this, as is so pertinently reflected in Eden's monumental study on "The State of the Poor" in England published in 1797, early researchers, as physicians, surgeons, administrators, clergymen and even landed aristocrats, were social reformers. Most were concerned to highlight the all too 
evident inequities in society. They drew attention to the unfair burdens brought about by taxation and systems of land tenure in their efforts to highlight the chronic plight of rural laborers and the urban underclass. Others, however, assumed a mercantilist mantle, demonstrating their concern to deliberate on matters of comparative wealth, rather than its distribution, and to relate national economic status, significantly, to the relative power of states.

In the 1930s and 1940s, governments in the West recognized their priorities were to create jobs and raise incomes. Their ability to control economic events using conventional information and policies with a predominantly micro emphasis first faced the reality of the Great Depression. Classical theory sent a message to cut wages to bring about an increase in employment which was evidently wrong, and complementary strategies to expand trade were also proving ineffective. Hostages more to misfortune and impotence than incompetence, policymakers were forced to take a more holistic view of the economy and to play a directly active role in the management of aggregate demand. Next, the need to mobilize resources for the war effort provided an imperative for macro economic management and the devastation wrought by the Second World War added urgency to looking at the whole economic structure. The task of rehabilitation and of building a requisite macroeconomic system depicting the circular flow of money and an accompanying database became an official responsibility and the national accounts emerged as a crucial policy tool. Despite recent high level discussions about the desirability of having a more flexible labor market, the primary goal of full employment, and thus of continued economic growth, remains a high priority on the political agenda of most countries.

The 1953 SNA (System of National Accounts) was a descriptive set of bookkeeping accounting balances depicting current outlays arranged against a relevant set of "incomings," with the residual balance from each table being transferred as a controlling total across to the next table that contained another related group of transactions. Thus, the "surplus" between gross output and intermediate expenditures arising from production activities could be shown distributed to the remuneration of labor, as unincorporated enterprise income, and to the gross operating surplus accruing to the corporate sector.

The 1968 SNA introduced (it might even be argued, in simpler logical form) a more complex system of inter-industry relationships. This portrayed, in detail, the composition of an intermediate demand that had been netted out of the earlier system. The core framework appeared quite similar to what the French had also been attempting to achieve in their own approach to input-output tables, as Chapter 2 reveals. The new system, with its distinct "make" and "absorption (use)" matrices, constituted a quantum leap over the "drop-down" sequence of aggregate balances and accounts in current prices previously adopted. The 1968 SNA represented a more pedagogic, technocratic structural vision of the economic mechanism. While this facilitated the simulation of different policy scenarios, use of the central input-output table relied on quasi auto-regressive procedures that rested initially on some basic mechanistic assumptions about the relative stability of various observed parameters depicted in the system. The framework permitted, for the first time, within a comprehensive statistical description of the macro economy, an integrated approach to both data collection and sector and factor analysis. One of several useful outcomes of the 1968 SNA was the development of extended 
Social Accounting Matrices (SAMs). These, by means of their unique "bespoke" national design, could present more clearly the potentially different impact of the structure of factor relations in production (and, hence, the effects of specific policy choices to expand output) on the spending patterns of particular groups in the community and demands for domestic and foreign goods when linked into a general equilibrium model. Later SAMs would also be used in several countries in a policy context to assess the estimated environmental impact of economic growth.

\section{The Authority of Theory}

However, in the 1968 SNA there was still no true symbiosis between micro and macro theory that would help explain the presence of competitiveness and productivity improvements, or satisfy expectations about how situations reported in successive years would reflect reality or help explain the changes observed between two periods. Analysts had to await further results from household survey research to incorporate varying elasticities and substitution effects, as well as price endogeneity in general, into their equations. As the volume of information expanded, the tensions between empirical observation and theory-evident from the time of Aukrust (1949) to Reich (2001) - have become more apparent. The desirability to highlight need as well as demand and to distinguish between value in use (consumption utility) versus value in exchange (revealed expenditure preferences) remains. The respective relevance to policy of market versus non-market production and the extent that individual levels of living are enhanced by the provision of non-market goods and services produced by the government and non-profit institutions for household sector consumption cannot be readily quantified. Non-market commodities are frequently undervalued but clearly have a marked impact on any consideration of personal living standards and communal welfare. The contribution of ICP (International Comparison Project) methodology to a better understanding of these types of outlays accruing to households and of purchasing power parities to an appreciation of the value of different consumption aggregates and, hence household welfare, has still to be fully exploited. The demands of policymakers to accommodate related questions within the same common conceptual valuation framework continue to pose major challenges for national accountants. An attempt to tackle these matters comprehensively and head on was first made in the 1993 SNA.

The 1993 SNA noted that macroeconomic accounts and micro databases were rarely compatible and that the former can seldom be built up by a simple aggregation of micro data. A key feature of the 1993 SNA was the determination to define the precise boundaries of production and the nature of real output. This meant identifying the appropriate price vectors and underlying price matrices that should be used in different sectors to deflate current price estimates, and was one of several key issues that preoccupied the attention of Peter Hill, the SNA's other principal author, who contributed much to the theoretical underpinning of the SNA. Questions about how to deal with quality change and productivity were examined by the Expert Group but no definitive answers were found that pleased or convinced everyone. Statisticians now generally acknowledge, however, that a quality improvement should be seen as a quantum change. The approaches most 
commonly adopted involve re-estimating values either econometrically using hedonic methods or subjectively on the basis of secondhand prices and the informed judgments of experts, all of which lead, implicitly, to a modification of the original nominal price.

In effect, if a commodity is considered to be twice as good as the one it replaces, even if it appears externally identical, then analysts argue the new price should be seen as half the actual market price reported. In other words, if a new pair of shoes costing the same price as those it replaces lasts twice as long, its "true" price should be deemed to be half the reported retail price. The difficulty with this approach is that it tries to link present quantums to past quantums in a way that only indirectly takes into account the concurrent prices of the old and new products in the market. It also does not take into account the extra input costs, some of which are intangible (such as invention and ingenuity), that may have gone into producing the better quality article.

\section{Adapting to Measure Real Change}

In contemporary practice, a particular problem arises insofar as quality and productivity improvements have been applied asymmetrically. In other words, where improvements can be estimated, they are introduced into the calculations. Similar adjustments in values have not been implemented to reflect changes in services output or made in those circumstances where there is an identifiable decline in product quality. A distortion in the resulting real estimates thus arises whenever derived prices and associated chain link indices are applied in practice to reported current values. The deflated output is no longer representative of the actual physical production recorded for some sectors. In other words, in a gross value context, there is an estimated "genuine output" (in terms of the potential utility satisfaction intrinsically imbedded in the output of new commodities) and a real physical production, authenticated by the actual number of units flowing off the end of the production line. The significance of this distinction is important for the links between actual output growth and employment generation, the measurement of inflation (specifically using GDP deflators), the meaning of capital-output ratios, the understanding of productivity change, the impact of technical progress, and the nature of the differences between public and private sector output. On the expenditure side, this treatment opens up an entirely different debate as to whether the calculated "quality" differential translates into an equivalent increase in utility —or is the quality effect simply a potential (mostly unused) capacity enhancement?

\section{Concepts, Constructs and Definitions}

Some of these problems arise from the difficulty of valuing capital. In the proposals for the next revision of the SNA, pressure is coming from several sources to treat the services of capital in the same way as labor and thus to introduce estimates of capital service inputs rather than simply make allowances annually for the consumption of capital. The latter conventionally treats plant and equipment as fixed assets that at some stage in their lifetime need to be replaced. The main advantage of adopting the proposed approach is that the SNA could then be used 
to generate multifactor productivity estimates of output per unit of both capital and labor inputs, rather than measures only of labor productivity as the accounts allow now (Moulton, 2004).

This proposal poses special problems for measuring the output of government and other producers of non-market goods and services, primarily because the equivalent rental value of capital cannot be unambiguously determined, even in such important and seemingly identifiable cases as housing, schools and hospitals. If countries choose to go down this route, then they should also consider how the accretion of new skills and knowledge enhances the value of human capital and improves the quality of labor service inputs. This point was initially made by Denison (1967) and taken up by Kendrick (1976). The approach has been rigorously restated more recently by, for example, Jorgenson et al. (1987) who indicate the way the accounts would need to change. Knowledge services seem to have a significant but difficult to detect effect, especially when imbedded in the technology and software supporting new production and changed systems of work organization. America is clearly in the vanguard of this advance and, for the forthcoming SNA, discussions may witness the unusual spectacle of U.S. officials implicitly endorsing an interpretation of human capital that is, if not explicitly a reconsideration of Marx's labor theory of value, then its seminal reinterpretation by Sraffa (1962).

A more fundamental question surrounding all these issues is how much should analysts ask the national accounts to take on? It can be argued there is already too much imputation in the figures and that while appropriate for conceptual coherence, imputed estimates, such as that for the production of own account consumption, or the value of owner occupied housing services, have very little practical application and no relevance to the determination of policy (unless there is some intention, say, to nationalize private property). Imputations tend to be useful only in rather narrower sector and topic specific micro contexts such as rural extension policies or general assessments of national nutritional standards. Statistically, where there is no overall "control" total, such as exists in the case of financial intermediation services indirectly measured, imputations are not much better than the assumptions that have been built into them.

There are several other concerns related to capital that demand attention. All, in a way, are connected to present SNA language and definitions. The concept and description of "gross fixed capital formation" was originally coined to capture what economic theory referred to as gross "investment." More than a half a century ago, researchers such as Seers (1963) were challenging the assumption that the statistical distinction between a consumption item and a capital good depended primarily on its effective durability, arbitrarily defined as a year. Seers argued that a luxury apartment (especially if it was a second property) was really part of consumption and that raising the wages of under-nourished workers could conceivably be treated as investment because the latter directly led to increased output whereas the former did not. Now this problem has reappeared, not just with software that clearly increases output and hi-tech goods that can prove obsolescent within twelve months, but with military hardware and consumer durables. In the case of military equipment, it is true many items display the characteristics of fixed assets in a strict statistical sense but can they really be described as assets that enjoy 
the same meaning as assets in the private sector? The latter contribute to an enhanced production capacity and represent net wealth. Appealing to the economic value of a potential civilian use for military hardware is little more than a smokescreen, given that such alternative usage has not taken place to any significant extent in the past. On this issue, even Trotsky's perspective on the nonproductive nature of "the destructive forces" seems appropriate. ${ }^{1}$

In a similar vein, there have been calls for a reappraisal of the role of natural capital - in particular, a call to value the services provided by resources as a factor of production, because, it is claimed, their contribution has been understated in conventional national accounting. This issue is also important to the compilation of comprehensive estimates of savings and wealth. Although the concept of "genuine savings" introduced by World Bank researchers (Hamilton and Clemens, 1997) moves positively in this direction, it is neither complete nor fully "genuine" in the sense used earlier to capture the increase in output that arises from improved quality.

Vanoli is sympathetic to this notion of genuine savings and sees ways in which the approach and concept can be refined and extended to embrace the vision of sustainability. Indeed, on this and the question of capital services, including those provided by consumer goods, he seems to favor a fuller assessment in satellite accounts, one of the developments in national accounting in which he played a pioneering part. On the other hand, the argument that expenditures on military equipment should be treated as capital outlays and, hence, as investment receives short shrift (see pp. 144, 311).

\section{The Establishment of a Universal Approach and Standard}

The path of progress in national accounting has not always been smooth; in fact, in a more turbulent past, to be engaged in the compilation of national statistics could prove quite threatening to personal liberty. Despite the intellectual legacy of the Enlightenment and prevalence of laissez-faire ideas, early French thinkers and researchers like Vauban and Boisguillebert were banished from court and their works destroyed. Later 18th century policymakers such as Turgot and Condorcet, primarily concerned to gather national economic data to help solve problems of unemployment and poverty, suffered worse fates. Leading Russian statisticians under the Czars were similarly punished and exiled as potential anarchists. Even in the U.S., Simon Kuznets, a true pioneer of national income accounting, faced long and tortuous disputes with the U.S. Department of Commerce on what approach to take, Denison argued over the (non)-treatment of capital in the government accounts and Leontief had his seminal input-output analysis put officially on hold in the 1950s because politicians - and their corporate supporters, one presumes - suspected this technique (because it followed Russian example) to be an instrument for implementing government planning.

Nevertheless, the end of the 20th century witnessed the demise of centrally planned systems and the onset of a freer political and economic democracy as governments around the world, perhaps under pressure in some cases from the

${ }^{1}$ See: www.marx2mao.com. 
Bretton Woods institutions, embraced the market and price system. This was, perhaps, an inevitable consequence of the increasing complexity of economies and spectacular growth in the volume of transactions. The two main lines of thought on production activity extending from Quesnay, through Adam Smith and David Ricardo to Marx and latter-day Soviet planners, and those of Marshall, Keynes, Colin Clark, Kuznets and the Bretton Woods institutions, began to merge. Building on the path-breaking data activities begun by the Hungarians to blend the structure of material balances belonging to the material product system (MPS) into the SNA, the process of fusing the different sources was carried out by a mostly anonymous group of dedicated official statisticians and international experts. A number of these were based at the UN(ECE) in Geneva which, for a long time, served as the only point of official contact between statisticians from the Eastern bloc and the West. The process of absorption extended beyond the more immediate goal of integration to one of full affiliation. It led eventually and logically to the rapid adoption of the SNA by the majority of centrally planned economies, thereby securing unique status for the SNA as a universal national accounting system.

\section{National Accounting and Distribution}

From the conceptual perspective, some questions about the bigger picture perhaps remain. Faced by the rising extent of current household and government debt, is it still possible to refer to the underlying economic logic of a real balance between consumption, income and production in the determination of gross national product (GNP) or its more recent nemesis, gross national income (GNI)? The continued spending beyond one's means is not just a problem of distinguishing between transactions and their method of financing. The traditional view is that production endogenously generates income that is spent on the goods and services generated by that current output. Now, to keep the system going, politically as much as economically, consumption is primed exogenously by a range of readily accessible policy tools. But such convenient fiscal or monetary instruments are often socially blunt, raising longer lasting concerns about their distributional impact on society and the downside effects of an excessive consumerism reinforced by the pressure of media induced advertising. Over the longer term, it is the sustainability of household well-being that may be put at risk.

There is also the very relevant and related question of how the national cake is distributed. This discussion has shifted significantly over the years from, first, an original concern with how the economy was structured and its activities segmented between agriculture, industry and services; then to a politico-economic interest in the composition of the value added and the distribution of the production "surplus" between the factors of production, capital and labor; to a present international preoccupation with the distribution of household income and expenditure, especially as it affects poverty. This illustrates how, in some countries, the political climate has changed, switching direction to reinforce the thrust of policy away from the primary pursuit of economic growth, with its potential for attendant employment and income generation in the formal economy, to a stronger emphasis on the delivery to different households, especially the poor, of "social" services like education and health. 
To some extent these different perspectives on distribution, as products of their era, have aspects in common. Particular economic activities were often concentrated in specific geographical locations and this affected the incomes of those living there, clearly giving rise to regional disparities in well-being and demands for regional accounts. But the concentration of industrial activities in particular places additionally made people vulnerable. Those employed in an undiversified economic environment were dependent on local industries for their survival. The maintenance of family living standards was exposed to the vagaries of the business cycle and any volatility in aggregate demand, for whatever reason. Some groups were especially squeezed by shifts in trade and comparative advantage, others by technological progress and by structural reform. Although all of this could be roughly mapped into the national accounts, the relevance, particularly long term, of education, health, research, and invention (or technical development) to both output and household well-being has proved far more of a problem to tie down, making it difficult to measure the distribution of personal income, let alone quantify the distribution of household welfare.

\section{Concluding Comments}

How far are the present challenges facing national accounting a question of inadequate data, or of an increasingly inappropriate conceptual framework or the existence of a system that has become less relevant to the contemporary modus operandi of economic policy? In many ways, the data are continually improving, although new legislation and changes in institutional arrangements have sometimes seriously affected the compilation of statistics. (A good example is the collection of trade data in the European Union, where new procedures had to be implemented in view of the statutory common customs area changes imposed under the wider policy perspective of a supra-national authority.) Changes in tax reporting and corporate legislation and outsourcing have also tended to undermine the continuity of data. Overall, while evidence suggests that data are collected more rapidly and effectively than in the past, it remains an article of faith whether they are more relevant.

Is the main problem then one of concepts and of a data system that is not keeping pace with the march of theoretical progress? As the discussion above indicates, there may be some truth in this assertion and the Review of Income and Wealth, in particular, regularly draws the attention of users and producers of such data to desirable changes and developments. Some of these require simple fine tuning but other issues, especially when related to concerns about incorporating welfare considerations and environmental degradation, raise more fundamental questions as to what a set of basically production accounts can or should present. The desire to keep abreast of economic thinking has been the prime motivation for successive revisions to the SNA from the earliest detailed but non-standardized back of the envelope calculations of national income and product in the late 1930s to the 1953, 1968, 1993 internationally endorsed systems. The latest 2006 revision is unlikely to detract from this responsibility to review and confront new theoretical concerns. 
The biggest question must be, however, whether national accounting still has prime order of place in a contemporary policy environment that is driven mostly by monetary instruments and performance targets and whose desired direction may sometimes be distorted by global events not under national control. In this latter respect, while the impact of most international activities eventually shows up in national data, there are some global transactions involving inter-agency and intra-corporate exchanges that transcend national boundaries. Consequently, they do not get captured in the conventional data gathering process.

The emphasis over the past decade on producing quarterly national accounts can be seen as an attempt to bring real economic issues back into the debate and for fiscal analysts to become more centrally engaged in the main thrust of current domestic policy rather than being solely preoccupied with raising revenues. But quarterly accounting is riddled with problems; the first estimates are all that really matter to such short term scenarios as interest rate decisions and these are the figures that, if statisticians are doing their jobs properly, are invariably subject to the most significant revision. This is particularly a concern where quarterly national accounts figures are used primarily to estimate current growth performance. These data are also weak because they include significant imputations, such as for housing services that (depending on the estimation methodology adopted) may or may not be ratcheted up to reflect speculative property market bubbles. Imputations generally tend to serve little policy purpose other than to confuse interpretations of the underlying economic situation and growth.

The political imperative to meet declared physical performance targets appears now to have precedence even over budgetary considerations with the result that governments are increasingly forced to borrow to cover deficits that have been partially brought about by ministerial spending as if there was no tomorrow. Such funding gaps, specifically in the social sectors, have almost exactly the opposite effect as the "pump priming" of deficit financing of a previous era, squeezing out private sector productive investment, adding stimulus to inflation and ultimately forcing ministries to close down some of the very services they most want to preserve.

The part the author has played in the process of strengthening the value of socioeconomic statistical systems to provide policy advice and his recollections of events and discussions surrounding key developments in the field of national accounting are well described in this book. Together, they form a substantial contribution to the intellectual history of national accounting. Vanoli, by his own admission, was not originally a statistician by training, but he nevertheless reveals the skills of an official Physiocrat well versed in the conventions and principles of an "ancien regime" of data compilation. To these he adds the incisive analytical dissection of a qualified lawyer and intellectual approach of a philosopher. It is to be earnestly hoped the author will continue to engage his attentions in the evolution and dissemination of ideas and to participate as a shaman in the crucial debates about the usefulness of national statistics for many years to come.

Michael Ward

Cambridge(mward39uk@yahoo.co.uk) 


\section{REFERENCES}

Aukrust, O., "On the Theory of Social Accounting," The Review of Economic Studies, XVI(3), No. 41, $1949-1950$

Blades, D., "A Brief History of the UN System of National Accounts," Mimeo, OECD, Paris, 2001.

Denison, E., Why Growth Rates Differ, The Brookings Institution, Washington, DC, 1967.

Eden, F. Morton, The State of the Poor, 3 volumes, J. Davis, London, 1797.

Hamilton, K. and M. Clemens, "Genuine Savings Rates in Developing Countries," World Bank Economic Review, 13(2), 1997.

Hill, P., The Measurement of Real Product, OECD, Paris, 1970.

Jorgenson, D., F. Gollop, and B. Fraumeni, Productivity and US Economic Growth, Harvard University Press, Cambridge, MA, 1987.

Kendrick, J., The Formation and Stocks of Total Capital, Columbia University Press for NBER, New York, 1976.

Moulton, B., "The System of National Accounts for the New Economy; What Should Change?" The Review of Income and Wealth, 50(2), June 2004.

Pyatt, G. and J. I. Round, Social Accounting Matrices: A Basis for Planning, The World Bank, Washington, DC, 1985.

Reich, Utz-Peter, National Accounts and Economic Value; A Study in Concepts, Palgrave, New York, 2001.

Ruggles, R. and Nancy Ruggles, "The Role of Micro Data in the National Economic and Social Accounts," The Review of Income and Wealth, 21(2), June 1975.

Seers, D., "The Limitations of the Special Case," Bulletin of the Institute of Economics and Statistics, 25(2), May 1963 (an extension of the ideas in this article was presented at the IARIW Conference in Corfu, 1963).

Sraffa, P., The Production of Commodities by Commodities, Cambridge University Press, 1962.

Szilagyi, G., "What is the Theory Behind? A Review of 'National Accounts and Economic Values' (Reich, 2001)," The Review of Income and Wealth, 49(2), June 2003.

Triplett, J. and B. Bosworth, Productivity in the US Services Sector: New Sources of Economic Growth, The Brookings Institution, Washington, DC, 2004.

Ward, M., Quantifying the World; UN Ideas and Statistics, United Nations Intellectual History Project, Indiana University Press, Bloomington, 2004. 